\title{
Continuous intravenous lidocaine infusion during isoflurane anaesthesia in horses undergoing surgical procedures
}

\author{
Maria Magdalena Schuhbeck, Mathias Kuhn, Claudia Spadavecchia and Olivier Lovis Levionnois
}

Wahlstedt private equine veterinary clinic, Wahlstedt, Germany and Section of Anaesthesiology, Departement of Clinical Veterinary Science, Vetsuisse Faculty, University of Bern, Switzerland

\begin{abstract}
Summary
The aim of the present study was to evaluate the adjunction of lidocaine as a continuous intravenous (IV) infusion during general anaesthesia with isoflurane in a clinical setting. For this purpose sixty horses (ASA I-III) undergoing elective surgery were assigned to a prospective, blinded, randomized clinical trial. After induction of anaesthesia, isoflurane end-tidal concentration was set at $1.3 \%$ and subsequently adjusted to maintain surgical plane of anaesthesia. Horses assigned to the group ISO-L $(\mathrm{n}=40)$ received IV lidocaine $\left(1.5 \mathrm{mg} \mathrm{kg}^{-1}\right.$, followed by $2.4 \mathrm{mg} \mathrm{kg}^{-1} \mathrm{hr}^{-1}$, reduced later to $2 \mathrm{mg} \mathrm{kg}^{-1} \mathrm{hr}^{-1}$ ) until 15 minutes before the end of the anaesthesia, while the control group ISO $(n=20)$ received physiologic saline solution. All horses were ventilated mechanically. Mean arterial pressure (MAP) was maintained over $70 \mathrm{mmHg}$ by IV infusion of dobutamine when necessary. Recovery quality was scored from one (very good) to five (very poor). The isoflurane concentration required in ISO-L group decreased down to $24 \%$ less $(1.2 \%$ vs. $1.57 \%, \mathrm{P}<0.05)$ than in the ISO group with time. Physiological parameters were similar in both groups. Recovery phases were scored of slight, but significant poorer quality $(P=0.034)$ in horses receiving lidocaine (2, IQR 1-3) than in the control group (1, IQR 1-2), although the quality was still acceptable. The use of a continuous IV infusion of lidocaine at 2-2.4 $\mathrm{mg} \mathrm{kg}^{-1} \mathrm{hr}^{-1}$ during general anaesthesia allowed for $24 \%$ reduction of the isoflurane requirement, without relevant difference in clinical cardiovascular parameters. Under the condition of the present study, the administration of lidocaine tended to reduce moderately the quality of recovery from anaesthesia.
\end{abstract}

Keywords: Anaesthesia, Analgesia, Isoflurane, Lidocaine, Intravenous

\section{Kontinuierliche intravenöse Lidocain-Infusion für chirurgische Eingriffe bei Pferden während Isofluran Narkose}

Ermöglicht eine Lidokain-Infusion eine Reduktion des Isofluranverbrauchs während der Narkose bei klinischen equinen Patienten ohne dabei gleichzeitig schlechtere Aufwachphase zu verursachen? In diese Studie wurden 60 Pferde einbezogen die für elektive chirurgische Eingriffe abgelegt wurden und in zwei Gruppen eingeteilt. Eine Gruppe bekam Isofluran (ISO) allein, die andere Gruppe bekam Isofluran in Kombination mit einer intravenösen Davertropfinfusion von Lidocain (ISO-L, Bolus: $1.5 \mathrm{mg} / \mathrm{kg}$; Erhaltung: $2.4 \mathrm{mg} \mathrm{kg}^{-1} \mathrm{~h}^{-1}$ ). Nach Prämedikation mit Romifidin und Narkoseeinleitung mit Diazepam und Ketamin wurden die Tiere orotracheal intubiert und an ein Kreissystem angeschlossen. Die endexspiratorische Isoflurankonzentration wurde auf $1.3 \%$ eingestellt und während der gesamten Narkosedauer angepasst, um ein Narkosestadium der chirurgischen Toleranz aufrechtzuerhalten. Nach 50 Minuten wurde die Infusionsrate des Lidocain auf $2 \mathrm{mg} \mathrm{kg}^{-1} \mathrm{~h}^{-1}$ reduziert und die Infusion 15 Minuten vor Narkoseende gestoppt. Die klinischen Standardparameter für Atmung und Kreislauf wurden aufgezeichnet. Durch mechanische Beatmung wurde der endexspiratorische $\mathrm{CO}_{2}-$ Wert auf $5,3 \mathrm{kPa}(40 \mathrm{mmHg}) \mathrm{gehalten}$. Der mittlere arterielle Blutdruck wurde über $70 \mathrm{mmHg}$ gehalten und wenn nötig durch Dobutamin Infusion unterstützt. Bei Anzeichen ungenügender Narkosetiefe (Nystagmus und/oder Bewegung), erhielten die Pferde Thiopental (0.5-1.5 mg kg-1). Bei Narkoseende erhielten die Pferde jeweils zusätzlich einen Bolus Romifidin $\left(0.01 \mathrm{mg} \mathrm{kg}^{-1}\right)$. Die Aufwachphase wurde bewertet von 1 (sehr gut) bis 5 (sehr schlecht). Die benötigte Isofluran Konzentration für die Pferde in der Gruppe ISO-L nahm während der gesamten Narkosedauer stetig ab, so dass nach $60 \mathrm{~min} 24 \%$ weniger Isofluran notwendig war (1.2\%), als in der reinen ISO-Gruppe (1.57\%). Die physiologischen Parameter waren in beiden Gruppen ähnlich. Die Bewertungen der Aufwachphase waren leicht aber signifikant unterschiedlich (P=0.034). In der ISO-L Gruppe war die Aufwachphase etwas länger, und mit niedrigerer Qualität (2, IQR 1-3 versus 1, IQR 1-2) als in der Kontrollgruppe. Durch die Kombination von Inhalationsnarkose (Isofluran) und einer intraoperativen Dauertropfinfusion von Lidocain wird der Isofluranverbrauch erheblich reduziert, aber die Aufstehphasequalität leicht aber signifikant verschlechtert.

Schlüsselwörter: Anästhesie, Narkose, Analgesie, Isofluran, Lidocain, intravenös

\section{Introduction}

The most negative effects of general inhalation anaesthesia using isoflurane leading to high perioperative morbidity rate are linked to the high concentration of the inhalant anaesthetics (Johnston et al. 1995) and their dose-dependent cardiopulmonary depression (Steffey 1978, Steffey et al. 1980). Moreover, the poor analgesic effect of such volatile anaesthetics leads to unstable cardiopulmonary parameters in response to surgical stimulation.
While there is still a marked response of the autonomic nervous system to surgical noxious stimuli when volatile anaesthetics are used alone (Roizen et al. 1981), systemically administered lidocaine further depress neuronal activity (Zhao et al. 2009) as a result of its antinociceptive properties. Partial intravenous anaesthesia (PIVA) combines volatile anaesthesia with the analgesic properties of intravenously administered anaesthetic and analgesic agents, with the aim of stabilizing the physiological parameters. This technique also aims at reducing prolonged recovery due to high dose of volatile or 
intravenous (IV) anaesthetics, while providing an adequate plane of surgical anaesthesia (Kushiro et al. 2005, Spadavecchia et al. 2002). In dogs, IV lidocaine infusion significantly reduced anaesthetic requirement (Matsubara et al. 2009, Muir et al. 2003, Steagall et al. 2006, Valverde et al. 2005, Wilson et al. 2008). Driessen (2005) reviewed early the potential of IV lidocaine CRI for equine PIVA and presented some personal experience with a reduced infusion rate (1.8 $\mathrm{mg} \mathrm{kg}^{-1} \mathrm{~h}^{-1}$ ) compared to previous publications (Doherty und Frazier 1998, Dzikiti et al. 2003) that used 3 to $6 \mathrm{mg}$ $\mathrm{kg}^{-1} \mathrm{~h}^{-1}$. Further investigations confirmed the ability of systemic administration of lidocaine to decrease dose-dependently anaesthetic requirements during general anaesthesia in horses (Rezende et al. 2011, Valverde et al. 2010) without intra-anaesthetic physiological or metabolic adverse effects (Valverde et al. 2010, Wagner et al. 2011), but with the risk at the recommended dosage $\left(3 \mathrm{mg} \mathrm{kg}^{-1} \mathrm{~h}^{-1}\right)$ to develop high plasma levels under general anaesthesia (Feary et al. 2005) and poor quality of the recovery phase (Valverde et al. 2005, Valverde et al. 2010). To our knowledge at the moment this study was performed, there were only two trials performed to compare the administration of lidocaine to a control group in a clinical setting (Dzikiti et al. 2003, Valverde et al. 2005), but using high dose of lidocaine and with different recovery methods.

The objective of this study was to investigate the sparing effect of lidocaine on inhalational anaesthetic requirement in a prospective clinical setting. We hypothesized that IV administration of lidocaine infusion between 2.0 and $2.4 \mathrm{mg} \mathrm{kg}^{-1} \mathrm{~h}^{-1}$ reduces the end-tidal isoflurane concentration required for general anaesthesia in horses undergoing elective sur-gery. Cardiopulmonary functions as well as qualitative recovery characteristics were also investigated for effect of treatment.

\section{Materials and Methods}

The present study received agreement of an internal ethics review committee and the owner consent for participation to the study and exploitation of the data was obtained for each horse included.

\section{Animals}

Sixty adult horses referred to a veterinary hospital for surgery were included in the trial. Horses assigned ASA status IV or V and pregnant mares were not included. Horses that underwent surgical procedures performed in less than 60 minutes were excluded from analysis and a new horse was then recruited. Animals were randomly assigned to receive one of the following anaesthetic maintenance protocols: twenty horses in the control group ISO, receiving isoflurane (Isoflo, Essex, Munich, Germany) combined with IV infusion of physiologic saline solution, and forty horses in the group L-ISO, receiving isoflurane combined with IV lidocaine (Lidocain 2\%, Albrecht, Aulendorf, Germany) continuous rate infusion. Food was withheld overnight, but access to water was always granted. After local surgical preparation, a 12-gauge, $8 \mathrm{~cm}$ long polypropylene catheter (Braunüle MT, B.Braun, Melsungen, Germany) was placed in one of the jugular vein before anaes- thesia. The anaesthetist was always the same and was unaware of the treatment administered.

\section{Anaesthetic technique}

The horses were premedicated with $80 \mu \mathrm{g} \mathrm{kg}{ }^{-1}$ romifidine (Sedivet, Boehringer Ingelheim Vetmedica, Ingelheim, Germany) IV and anaesthesia was induced with $0.1 \mathrm{mg} \mathrm{kg}^{-1}$ diazepam (Diazepam 10, Ratiopharm GmbH, Ulm, Germany) and $3 \mathrm{mg} \mathrm{kg}^{-1}$ ketamine (Ursotamin, Serumwerk Bernburg AG, Germany) IV. Endotracheal intubation was performed (28 mm diameter, Willy Rüsch GmbH, Kernen, Germany) and the tube connected to a large animal anaesthetic circle system equipped with a mechanical ventilator (Stephan-Respirator GT, F. Stephan Gmbh, Gackenbach, Germany). Intermittent positive pressure ventilation was set to a respiratory rate of five breaths $\mathrm{min}^{-1}$ and a peak inspiratory airway pressure of $25 \mathrm{cmH}_{2} \mathrm{O}$. Respiratory rate was further adjusted to maintain $\mathrm{ET} \mathrm{CO}_{2}$ at around $5.3 \mathrm{kPa}(40 \mathrm{mmHg})$. Isoflurane was administered in pure oxygen $\left(6 \mathrm{~L} \mathrm{~min}^{-1}\right)$ and regulated until an end-tidal concentration of $1.3 \%$ was achieved. Within the 10 first minutes of general anaesthesia, the target was reached and the isoflurane concentration was then adjusted according to the anaesthetic depth (see below). Shortly after endotracheal intubation, horses in the L-ISO group received a loading dose of lidocaine IV $\left(1.5 \mathrm{mg} \mathrm{kg}^{-1}\right)$ over ten minutes, followed by a continuous rate infusion of lidocaine (2.4 $\left.\mathrm{mg} \mathrm{kg}^{-1} \mathrm{~h}^{-1}\right)$ diluted in isotonic saline $(\mathrm{NaCl} 0.9 \%)$ solution administered with an infusion syringe pump (Perfusor secura, B.Braun, Melsungen, Germany). After 50 minutes, the infusion rate was decreased to reduce the dose of lidocaine to 2 $\mathrm{mg} \mathrm{kg}^{-1} \mathrm{~h}^{-1}$. Infusion was stopped 15-20 minutes before the end of anaesthesia.

\section{Monitoring}

Heart rate (HR) was derived from the electrocardiogram. Systolic, diastolic and mean arterial pressure (SAP, DAP, MAP) measured from a catheter inserted into the facial artery and connected to a calibrated pressure transducer (Novatrans II MX860, Medex Gmbh, Düsseldorf, Germany) were continuously monitored and recorded (Dräger PM 8014-8050, Drägerwerk AG, Lübeck, Germany). Respiratory gases were continuously sampled from the distal end of the endotracheal tube and respiratory rate (RR), end-tidal concentration of isoflurane (FE'ISO) and end-tidal partial pressure of carbon dioxyde $\left(\mathrm{PE}^{\prime} \mathrm{CO}_{2}\right)$ were automatically analyzed using the Dräger PM 8014-8050 monitor (Drägerwerk AG, Lübeck, Germany). The gas analyser was calibrated following the instructions of the manufacturer. Arterial blood samples were anaerobically collected every 30 minutes from the facial artery catheter and immediately analyzed (ABL TM5, Radiometer Medical A/S, Kopenhagen, Denmark) for arterial $\mathrm{pH}$ and partial pressure of $\mathrm{CO}_{2}\left(\mathrm{PaCO}_{2}\right)$ and $\mathrm{O}_{2}\left(\mathrm{PaO}_{2}\right)$ with correction for body temperature. Minute volume (MV) and peak inspiratory airway pressure (PIP) were monitored at each breath (Capnomac Ultima ${ }^{\mathrm{TM}}$, Datex-Ohmeda, Helsinki, Finland). Dobutamine (Dobutamin solvay, Solvay Arzneimittel, Hannover, Germany) was infused IV to effect in order to maintain MAP over $70 \mathrm{mmHg}$. Every five minutes, the dobutamine dose was adjusted: increased by $0.25 \mu \mathrm{g} \mathrm{kg}^{-1} \mathrm{~min}^{-1}$ 
when MAP decreased or remained below $70 \mathrm{mmHg}$; maintained at the same dosage when MAP ranged between 70 and $80 \mathrm{mmHg}$ or increased from below to above $60 \mathrm{mmHg}$; decreased by $0.25 \mu \mathrm{g} \mathrm{kg}-1 \mathrm{~min}^{-1}$ when MAP increased from below to above $70 \mathrm{mmHg}$; completely stopped when MAP went above $80 \mathrm{mmHg}$.

\section{Maintenance of anaesthesia}

The end-tidal isoflurane concentration was adjusted to maintain a light surgical plane of anaesthesia. According to a scoring chart (Fig. 1), the anaesthesia depth was scored every five minutes between -1 (deep anaesthesia) and +4 (very light anaesthesia) based upon clinical and physiological parameters and the end-tidal isoflurane concentration adjusted as required. As surgical stimulations could have been inconsistent within these five minutes periods, the anaesthetist attempted to score during the stimulations rather than during surgical pauses in order to avoid a non-surgical plane of anaesthesia (too low isoflurane concentration). According to the presence of movement (score 3 or 4), nystagmus (score 2), palpebral reflex (score -1 to 1) and variation in MAP (score 0 or 1 ), the vaporizer setting was adapted to achieve a new end-tidal isoflurane concentration. A score of 1 was assigned when absence of nystagmus and presence of marked palpebral reflex were associated with an increase in MAP, compared to a reference value. For each horse, the reference value was the MAP under anaesthesia just before the first surgical incision. To reflect isoflurane requirements in each groups, the percentage of the total anaesthesia time spent at each end-tidal isoflurane concentration was calculated for each horse and averaged per group. All the animals received romifidine $\left(10 \mu \mathrm{g} \mathrm{kg}^{-1}, \mathrm{IV}\right)$ before recovering under observation but unassisted. Time to swallowing, to achieve sternal recumbency and to standing position were recorded. Recovery quality was scored from one (very good) to five (very poor), according to the following scale: One, horse standing at first attempt in less than 60 minutes with minimal ataxia; two, horse standing at first or second attempt in less than 60 minutes with moderate ataxia; three, horse standing after more than two attempts, showing marked ataxia or lasting more than 60 minutes; four, horse standing with marked ataxia and mild injuries; five, horse standing with considerable ataxia or with major complication (wound, muscle trauma, excitation).

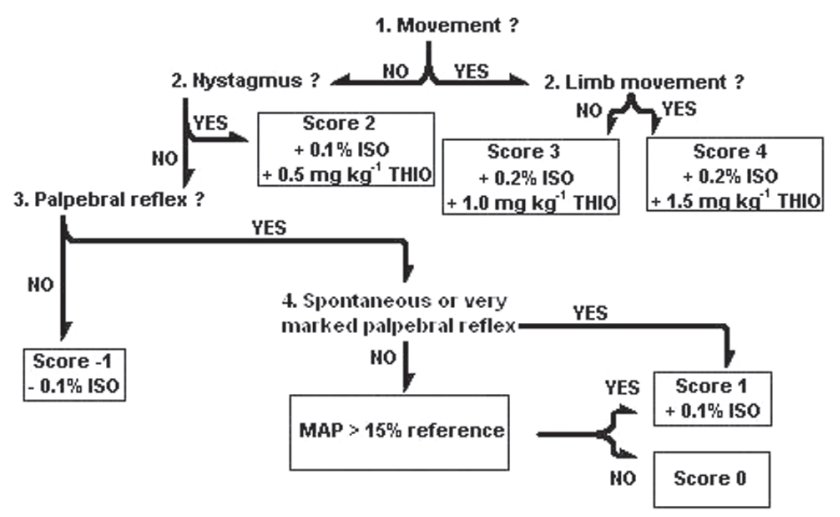

Fig. 1 Scoring for depth of anaesthesia. This flow-chart represents the scoring system used to adjust anaesthetic requirement in order to maintain light surgical depth of anaesthesia. Questions 1. to 3. are answered by yes or no to obtain the score, the modification of the isoflurane concentration (ISO) and the intravenous administration of thiopentone (THIO). MAP: Mean Arterial Pressure.

Beurteilung der Anästhesietiefe. Dieses Diagram zeigt wie die Narkosetiefe anhand einer Skala von - 1 (tief) bis 4 (sehr wach) beurteilt wurde. Die Isoflurankonzentration ist damit angepasst worden, um eine leichte chirurgische Narkosetiefe zu erhalten (Score 0). Frage 1. bis 3. sind mit Ja oder Nein zu beantworten. MAP: mittlerer arterieller Blutdruck.

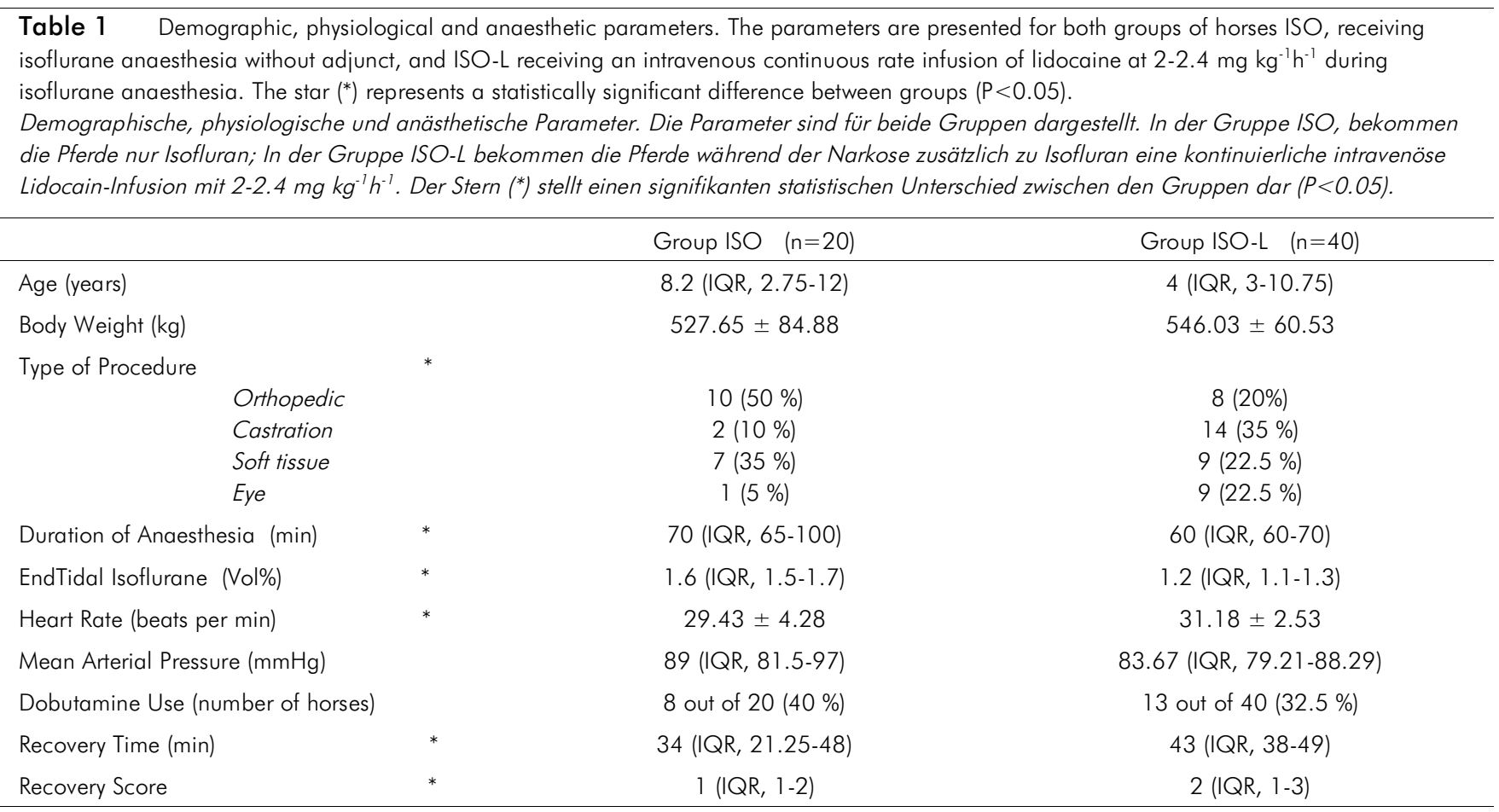


All the statistical analysis was performed using dedicated statistical software (Sigmastat for Windows, Systat Software Inc, USA). For all data, a Kolmogorov-Smirnov test was used to proof normality $(\mathrm{P}<0.05)$. Normally distributed data were represented as mean \pm standard deviation, and non parametric data were represented as median and interquartile range (IQR). Significant differences between groups for the

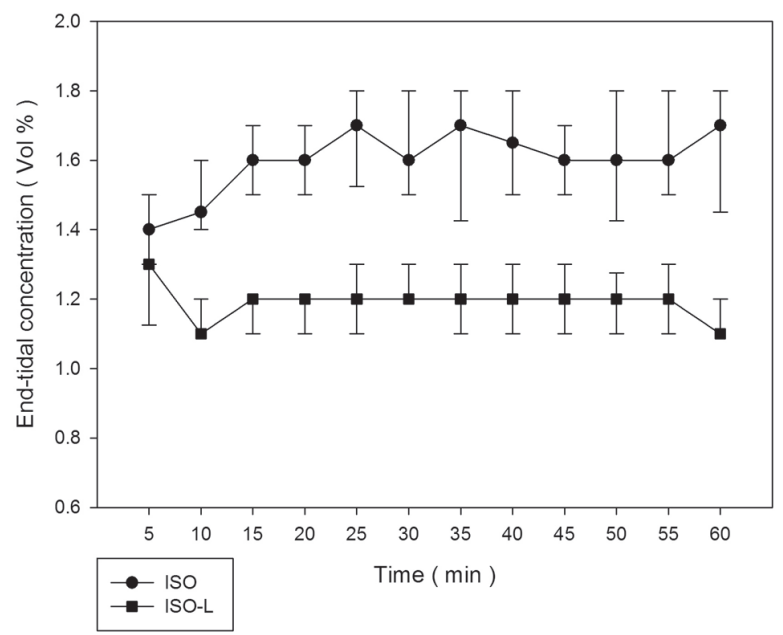

Fig. 2 End-tidal isoflurane concentration. This graph represents the end-tidal isoflurane concentration (Volume per cent) over time in both groups of horses (ISO, receiving isoflurane anaesthesia without adjunct, and ISO-L receiving an intravenous continuous rate infusion of lidocaine during isoflurane anaesthesia).

End-expiratorische Isoflurankonzentration. Diese Graphik zeigt die mediane end-expiratorische Isoflurankonzentration (Vol\%) während der Narkose bei den beiden Gruppen ISO und ISO-L.

proportions of types of surgical interventions and number of horses requiring dobutamine support were analysed with a Chi-Square test $(P<0.05)$. Significant differences between groups for single parametric data (weight) were analysed with a Student- $t$ test $(P<0.05)$. Significant differences between groups for single non parametric data (age, anaesthesia duration, recovery duration and recovery score) were analysed with a Mann-Whitney Rank Sum test $(P<0.05)$. Significant differences between groups for repeated measures of parametric data (HR) were analysed with a two-way ANOVA for repeated measures.

\section{Results}

Twenty horses aged 8.2 (IQR, 3-12) years-old and weighting $528 \pm 85 \mathrm{~kg}$ body weight were included in the group ISO. Forty horses aged 4 (IQR, 3-11) years-old and weighting $546 \pm 61 \mathrm{~kg}$ body weight were included in the group ISO-L. No difference was found between the groups for age $(P=0.403)$ nor weights $(P=0.338)$. The group ISO received significantly $(P=0.005)$ longer anaesthetic procedures compared to the ISO-L group, lasting 70 (IQR, 65-100) minutes and $60(I Q R, 60-70)$ minutes, respectively. Six horses from group ISO and 4 from group ISO-L were maintained under general anaesthesia for longer than 90 minutes. The type of 
surgical procedure were significantly different between groups (Table 1, $\mathrm{P}=0.016)$. Values for respiratory parameters (RR, TV, End-Tidal CO2) and blood gas analysis remained within normal ranges and no statistical significant differences were found between groups. Values for MAP also remained within normal ranges in both groups ISO with 89 (IQR, 82-97) $\mathrm{mmHg}$ and ISO-L with 84 (IQR, 79-88) $\mathrm{mmHg}$. The difference did not reach statistical significance $(P=0.108)$. The number of horses requiring dobutamine to support the mean arterial blood pressure was also not significantly different $(P=0.774)$ between groups with $40 \%$ of horses within the ISO group and $32.5 \%$ of horses within the ISO-L group (Table 1). The mean heart rate did differ significantly $(P=0.031)$ between groups with $29 \pm 4$ beats per minute for the ISO group and $31 \pm 3$ beats per minute for the ISO-L group. Mean isoflurane requirement was significantly higher $(P<0.001$, Fig. 2) in the ISO group with $1.6(I Q R$, 1.5-1.7) Vol\% than in the ISO-L group with 1.2 (IQR, 1.11.3) Vol\%. This corresponds to a reduction of isoflurane requirement by approximately $25 \%$ using the lidocaine IV CRI. The time necessary from the end of the anaesthesia until the horse was standing was significantly longer $(P=0.015)$ for horses in the group ISO-L with 44 (IQR, 38-49) minutes than for the horses in the group ISO with 34 (IQR, 21-48) minutes. Moreover, the quality of recovery was judged to be significantly better $(P=0.034)$ for horses in group ISO with a score of 1 (IQR, 1-2) versus 2 (IQR, 1-3) for horses in group ISO-L. In both groups one horse was scored a recovery quality of 4 .

\section{Discussion}

As hypothesized, the horses receiving an intravenous constant-rate infusion of lidocaine in combination with isoflurane anaesthesia required $25 \%$ less isoflurane than horses anaesthetised with isoflurane alone. The depth of anaesthesia and the mean arterial blood pressure values were maintained at good levels comparavly in both groups and needed only little dobutamine addition.

Even though lidocaine is highly metabolized in the liver and has a short half-life (Engelking et al. 1987), it has been described that discontinuing the intravenous infusion shortly before the end of anaesthesia helps to avoid adverse drug response. In fact, the pharmacokinetic of lidocaine is influenced by general anaesthesia and higher plasma levels as well as delayed elimination is expected (Feary et al. 2005). In a previous study from Valverde et al. (2005) recovery times and quality in horses undergoing general anaesthesia with additional lidocaine infusion were evaluated by investigators unaware of the treatment. It was noticed that horses receiving lidocaine until the end of the surgery had a significantly higher degree of ataxia and a tendency for a lower quality of recovery. However, no sedation was administered during recovery, lidocaine was administered at $3 \mathrm{mg} \mathrm{kg}^{-1} \mathrm{~h}^{-1}$ and ketamine and xylazine were administered when inhalant anaesthesia was discontinued. In another study, Ringer et al. (2007) continued lidocaine infusion until the end of anaesthesia and compared it to medetomidine, a powerful sedative, showing that lidocaine induced more ataxia during recovery. In the present study, the lidocaine dose was reduced (2$2.4 \mathrm{mg} \mathrm{kg}^{-1} \mathrm{~h}^{-1}$ ) compared to previous studies. This dosage is within the range of the recommended dosages by Malone et al. (2006) and Doherty and Frazier (1998) and plasma levels are expected to be maintained below predicted toxicity. Moreover, the CRI was discontinued 15 minutes prior to the end of anaesthesia and romifidine was administered in the recovery box. However, the recovery time was still significantly longer and the subjective recovery score significantly increased (worse) in the group receiving lidocaine. Still, the recovery quality was acceptable (recovery score $<4$ ) in most cases including horses receiving lidocaine. The relatively short duration of anaesthesia (mostly below 90 minutes) is also to be considered.

Surgical anaesthesia commonly required 1.2-1.4 times the minimum alveolar concentration (MAC) when using inhalation anaesthesia. For isoflurane, MAC is close to $1.2 \%$ in horses (Steffey et al. 1977). Therefore, FE'ISO often reaches $1.6 \mathrm{Vol} \%$ during surgical anaesthesia. In the present study, lidocaine CRI allowed for reduction to 1.2Vol\%. This result correlates with MAC reduction of volatile agents in the studies of Doherty and Frazier (1998) for 20\% of halothane use under experimental condition, and $25 \%$ of isoflurane use by Dzikiti et al. (2003) in a clinical setting where $2.5 \mathrm{mg} \mathrm{kg}^{-1}$ followed by $3 \mathrm{mg} \mathrm{kg-1} \mathrm{h-1} \mathrm{of} \mathrm{lidocaine} \mathrm{was} \mathrm{administered.} \mathrm{When}$ ketamine and lidocaine infusions are added to isoflurane anaesthesia, the isoflurane requirement can be further reduced down to $1.0 \%$ (Enderle et al. 2008). This was confirmed by Villalba et al. (2011) where the addition of morphine did not further reduce the anaesthetic requirement. Enderle et al. (2008) reported that volatile anaesthesia with isoflurane and additional intravenous lidocaine and ketamine CRI results in a more stable anaesthesia with less undesirable cardiovascular depression. The sedative and analgesic activity of lidocaine was also demonstrated in conscious horses (Malone et al. 2006, Milligan et al. 2007). In the present study, different types of surgical intervention were performed between groups with potentially various noxious intensities. It cannot be determined if the procedures performed in the group ISO were significantly more painful, and responsible for the higher isoflurane requirements. Even though this hypothesis is considered improbable by the authors, it is to be noted that the types of surgery were not identical between groups.

According to the absence of undesirable intra-anaesthetic effect reported here as well as in several other studies, lidocaine can be recommended for routine use as adjunct to isoflurane anaesthesia in horses. Although there is a relevant potential for more ataxia in the recovery, the benefits of lidocaine to significantly reduce the requirement for volatile agent under general anaesthesia has been well documented and meets medical, economical and safety issues. Several other properties have been mentioned for systemic administration of lidocaine, like cellular and biochemical effects on intestinal smooth muscle, blockade of inhibitory spinal and peritoneal sympathetic reflexes, inhibition of central hyperalgesia, anti-inflammatory and antiendotoxic actions (Brianceav et al. 2002, Doherty und Seddighi 2010, Malone et al. 2006, Peiro et al. 2010, Robertson et al. 2005, Van Hoogmoed 2003) suggesting other interesting benefits for lidocaine administration.

To conclude, the present clinical study confirmed previous experimental investigations, that lidocaine can be administered intravenously as a routine adjunct to isoflurane general 
anaesthesia in horses allowing for reduction of the volatile anaesthetic requirement from 1.6 down to $1.2 \mathrm{Vol} \%$. All horses were ventilated and the cardiovascular depression was similar with or without lidocaine. When stopping lidocaine administration 15 minutes before the end of anaesthesia, administering lower infusion rates and sedating the horse, the recovery phase was maintained at acceptable quality but tended to be prolonged and induce more ataxia than without lidocaine.

\section{References}

Brianceau P., Chevalier H., Karas A., Court M. H., Bassage L., KirkerHead C., Provost P. and Paradis M. R. (2002) Intravenous lidocaine and small-intestinal size, abdominal fluid, and outcome after colic surgery in horses. J. Vet. Intern. Med. 6, 736-741

Doherty T. J. and Frazier D. L. (1998) Effect of intravenous lidocaine on halothane minimum alveolar concentration in ponies. Equine Vet. J. 4, 300-3333

Doherty T. J. and Seddighi M. R. (2010) Local anesthetics as pain therapy in horses. Vet. Clin. North Am. Equine Pract. 3, 533-549

Driessen B. (2005) Intravenous lidocaine infusion in balanced anaesthesia for abdominal surgery: update and clinical experiences. Pferdeheilkunde 2, 133-141

Dzikiti T. B., Hellebrekers L. J. and van Dijk P. (2003) Effects of intravenous lidocaine on isoflurane concentration, physiological parameters, metabolic parameters and stress-related hormones in horses undergoing surgery. J. Vet. Med. A Physiol. Pathol. Clin. Med. 4, 190-195

Enderle A. K., Levionnois O. L., Kuhn M. and Schatzmann U. (2008) Clinical evaluation of ketamine and lidocaine intravenous infusions to reduce isoflurane requirements in horses under general anaesthesia. Vet. Anaesth. Analg. 4, 297-305

Engelking L. R., Blyden G. T., Lofstedt J. and Greenblatt D. J. (1987) Pharmacokinetics of antipyrine, acetaminophen and lidocaine in fed and fasted horses. J. Vet. Pharmacol. Ther. 1, 73-82

Feary D. J., Mama K. R., Wagner A. E. and Thomasy S. (2005) Influence of general anesthesia on pharmacokinetics of intravenous lidocaine infusion in horses. Am. J. Vet. Res. 4, 574-580

Johnston G. M., Taylor P. M., Holmes M. A. and Wood J. L. (1995) Confidential enquiry of perioperative equine fatalities (CEPEF-1): preliminary results. Equine Vet. J. 3, 193-200

Kushiro T., Yamashita K., Umar M. A., Maehara S., Wakaiki S., Abe R., Seno T., Tsuzuki K., Izumisawa Y. and Muir W. W. (2005) Anesthetic and cardiovascular effects of balanced anesthesia using constant rate infusion of midazolam-ketamine-medetomidine with inhalation of oxygen-sevoflurane (MKM-OS anesthesia) in horses. J. Vet. Med. Sci. 4, 379-384

Malone E., Ensink J., Turner T., Wilson J., Andrews F., Keegan K. and Lumsden J. (2006) Intravenous continuous infusion of lidocaine for treatment of equine ileus. Vet. Surg. 1, 60-66

Matsubara L. M., Oliva V. N., Gabas D. T., Oliveira G. C. and Cassetari M. L. (2009) Effect of lidocaine on the minimum alveolar concentration of sevoflurane in dogs. Vet. Anaesth. Analg. 5, 407-13

Milligan M., Beard W., Kukanich B., Sobering T. and Waxman S. (2007) The effect of lidocaine on postoperative jejunal motility in normal horses. Vet. Surg. 3, 214-220

Muir W. W. 3rd, Wiese A. J. and March P. A. (2003) Effects of morphine, lidocaine, ketamine, and morphine-lidocaine-ketamine drug combination on minimum alveolar concentration in dogs anesthetized with isoflurane. Am. J. Vet. Res. 9, 1155-1160

Peiro J. R., Barnabe P. A., Cadioli F. A., Cunha F. Q., Lima V. M., Mendonca V. H., Santana A. E., Malheiros E. B., Perri S. H. and Valadao C. A. (2010) Effects of lidocaine infusion during experimental endotoxemia in horses. J. Vet. Intern. Med. 4, 940-948

M. L. Rezende, Wagner A. E., Mama K. R., Ferreira T. H. and Steffey E. P. (2011) Effects of intravenous administration of lidocaine on the minimum alveolar concentration of sevoflurane in horses. Am. J. Vet. Res. 4, 446-451
Ringer S. K., Kalchofner K., Boller J., Fürst A. and Bettschart-Wolfensberger R. (2007) A clinical comparison of two anaesthetic protocols using lidocaine or medetomidine in horses. Vet. Anaesth. Analg. 4, 257-268

Robertson S. A., Sanchez L. C., Merritt A. M. and Doherty T. J. (2005) Effect of systemic lidocaine on visceral and somatic nociception in conscious horses. Equine Vet. J. 2, 122-127

Roizen M. F., Horrigan R. W. and Frazer B. M. (1981) Anesthetic doses blocking adrenergic (stress) and cardiovascular responses to incision - MAC BAR. Anesthesiology 5, 390-398

Spadavecchia C., Stucki F., Moens Y. and Schatzmann U. (2002) Anaesthesia in horses using halothane and intravenous ketamineguaiphenesin : a clinical study. Vet. Anaesth. Analg. 20-28

Steagall P. V., Teixeira Neto F. J., Minto B. W., Campagnol D. and Correa M. A. (2006) Evaluation of the isoflurane-sparing effects of lidocaine and fentanyl during surgery in dogs. J. Am. Vet. Med. Assoc. 4, 522-527

Steffey E. P. and Howland D. Jr. (1978) Cardiovascular effects of halothane in the horse. Am. J. Vet. Res. 4, 611-615

Steffey E. P. and Howland D. Jr. (1980) Comparison of circulatory and respiratory effects of isoflurane and halothane anesthesia in horses. Am. J. Vet. Res. 5, 821-825

Steffey E. P., Howland D. Jr., Giri S. and Eger E. I. 2nd (1977) Enflurane, halothane, and isoflurane potency in horses. Am. J. Vet. Res. 7, 1037-1039

Valverde A., Gunkel C., Doherty T. J., Giguere S. and Pollak A. S. (2005) Effect of a constant rate infusion of lidocaine on the quality of recovery from sevoflurane or isoflurane general anaesthesia in horses. Equine Vet. J. 6, 559-564

Valverde A., Gunkelt C., Doherty T. J., Giguere S. and Pollak A. S. (2005) Effect of a constant rate infusion of lidocaine on the quality of recovery from sevoflurane or isoflurane general anaesthesia in horses. Equine Vet. J. 6, 559-564

Valverde A., Rickey E., Sinclair M., Rioja E., Pedernera J., Hathway A. and Cruz A. (2010) Comparison of cardiovascular function and quality of recovery in isoflurane-anaesthetised horses administered a constant rate infusion of lidocaine or lidocaine and medetomidine during elective surgery. Equine Vet. J. 3, 192-199

Van Hoogmoed L. M. (2003) Clinical application of prokinetics. Vet. Clin. North Am. Equine Pract. 3, 729-740, vii

Villalba M., Santiago I. and Gomez de Segura I. A. (2011) Effects of constant rate infusion of lidocaine and ketamine, with or without morphine, on isoflurane MAC in horses. Equine Vet. J. 6, 721-726

Wagner A. E., Mama K. R., Steffey E. P., Ferreira T. H. and Rezende M. L. (2011) Comparison of the cardiovascular effects of equipotent anesthetic doses of sevoflurane alone and sevoflurane plus an intravenous infusion of lidocaine in horses. Am. J. Vet. Re.s 4, 452-460

Wilson J., Doherty T. J., Egger C. M., Fidler A., Cox S. and Rohrbach $B$. (2008) Effects of intravenous lidocaine, ketamine, and the combination on the minimum alveolar concentration of sevoflurane in dogs. Vet. Anaesth. Analg. 4, 289-296

Zhao F., Williams M., Welsh D. C., Meng X., Ritter A., Abbadie C., Cook J. J., Reicin A. S., Hargreaves R. and Williams D. S. (2009) FMRI investigation of the effect of local and systemic lidocaine on noxious electrical stimulation-induced activation in spinal cord. Pain 1-2, 110-119

Olivier L. Levionnois

DVM, Dr. med. vet, Dipl. ECVAA, PhD

University of Bern

Vetsuisse Faculty (Veterinary Hospital of Bern)

Department of Clinical Veterinary Sciences

Veterinary Anaesthesiology and Pain Therapy

Länggassstrasse 124

Postfach 8466

3001 Bern

Schweiz

olivier.levionnois@vetsuisse.unibe.ch 